EPiC Series in Education Science
Volume 3, 2020, Pages 200-203
Proceedings of the MIT LINC 2019 Conference

\title{
Self-sustaining Crowdsourcing: Beyond the Wikipedia Model to Make pk-12 Computer Science Education Universal in Developing Countries
}

\author{
Armando Sanchez and Javier Peraza \\ Progracademy \\ armando.sanchez@progracademy . org, javier . peraza@progracademy • org
}

\begin{abstract}
Progracademy (PRG) is a program that seeks to make universal the development of 21 st-century competencies (6Cs) -with emphasis on computational ones, in underprivileged pK-12 students of developing countries. PRG proposes a selfsustaining crowdsourcing solution applied to education, with the two key innovative components: i) extra-supported online Computer Science courses (MaxiMOOCs on Collaborative Programming) for pK-12 students who work in teams during school time (PRG Lab) and/or after school (PRG Club), and ii) an online platform that empowers and coordinates online volunteers, teachers, and parents in order to support students. PRG is a solution for underprivileged schools' severe limitations of resources and institutional capacity to develop 6Cs in students. PRG's seeks a quadruple social impact at scale and cost-effectively: i) achieve students' 6Cs educational objectives, ii) build capacity in the schools' teachers and administrators to educate in 6Cs, iii) develop 6Cs in the volunteers that support the students, and iv) mobilize sustainable support from the for-profit sector and civil society to the public education system. After a successful pilot in a Venezuelan school belonging to the largest educational NGO in Latin America-Fe y Alegria, PRG is now being piloted in Ecuador in two schools from the same NGO.
\end{abstract}

\section{Progracademy's objectives}

Progracademy (PRG) is an initiative aimed to make 6Cs universal, with special emphasis on computational competencies, among underprivileged pK-12 students in developing countries. We call 
6Cs to the following competency areas: critical and creative thinking, communication, collaboration, character/citizenship, and computing, most of which are in tune with Deep Learning [1]. The development of $6 \mathrm{Cs}$ is a daunting task in developing countries, which are already facing an acute learning crisis in the basic competencies (3Rs: reading, writing numeracy) where they lag far behind developed countries. Such "100-year gap" [2] is likely to worsen due to technological change acceleration. PRG helps to close that educational attainment gap by providing a self-sustaining crowdsourcing solution that can overcome the severe resource and institutional capacity limitations faced by the traditional school systems in developing countries when trying to educate in the 6Cs. Those 6Cs are personified in the three attributes of PRG's graduate profile. To develop those attributes, we propitiate in students three instrumental learnings, 24 competencies, and six habits:

\begin{tabular}{|c|c|c|}
\hline Instrumental learning $\rightarrow$ & Habits to be developed $\rightarrow$ & $\begin{array}{c}\text { Graduate profile } \\
\text { attributes }\end{array}$ \\
\hline $\begin{array}{l}\text { Autonomous learning } \\
\text { (learn to learn) }\end{array}$ & $\begin{array}{l}\text { Deliberate practice and } \\
\text { Growth mindset }\end{array}$ & $\begin{array}{l}\text { Permanent learners } \\
\text { (i.e., lifelong learners) }\end{array}$ \\
\hline $\begin{array}{l}\text { Collaborative learning } \\
\text { (learn to collaborate to learn) }\end{array}$ & $\begin{array}{c}\text { Change agency and } \\
\text { Collaborative problem solving }\end{array}$ & Collaborative leaders \\
\hline $\begin{array}{l}\text { Computational learning } \\
\text { (learn Computer Science) }\end{array}$ & $\begin{array}{l}\text { Computational thinking and } \\
\text { Design Thinking }\end{array}$ & Computational creators \\
\hline
\end{tabular}

PRG's impact goes beyond having the students achieve the above-mentioned 6Cs educational objectives in a cost-effective and scalable way. PRG also impacts the educational community, especially teachers and parents, and online volunteers, especially coaches. Teachers' objectives include their development as facilitators of autonomous and collaborative learning. Coaches' objectives include the development of their "Collaborative Leader" and "Permanent Learner" attributes, crucial for their own careers [3]. Finally, PRG's impact also includes catalyzing the sustainable, direct support from the private sector and civil society to public pK-12 education.

\section{Implementation during 2017-2019 and model description}

For the proof of concept in Venezuela (Mar'17-Jun'17), PRG was implemented in one school and served 100 6th -grade students (11-years-olds). In the current replicability pilot in Ecuador (Oct'18-Jun'19), PRG is being implemented in two schools and is serving 183 7th -grade students (11-year-olds), with the support of the Inter-American Development Bank. All the schools served belong to the largest educational NGO in Latin America -Federación Internacional Fe y Alegría.

PRG is an online education ecosystem based on self-sustaining crowdsourcing via two innovations: one in Educational Technology (Collaborative Programming MaxiMOOCs for pK-12 students) and one in Social Collaboration (an online platform that empowers volunteers, teachers, and parents, and coordinates their support in the MaxiMOOCs). The MaxiMOOCs are provided within two integrated programs: the formal education program, in which students work in teams from their schools' computer labs during school time (PRG Lab, since Mar'17), and the informal education program, in which students work online after school (PRG Club, since Dec'18). In the third integrated program -PRG Hub, planned for 2021, beneficiaries will be empowered as entrepreneurs that provide 
remunerated ICT and ICT-education services. Two key elements of the model are its crowdsourcing setup and its pedagogical strategies.

2.1 Crowdsourcing based on functions disaggregation and coordination: In the traditional teacher-led model most educational functions are concentrated on the teacher. Instead, PRG's student-centered model disaggregates those functions so they can be crowdsourced from Facilitators (online coaches, school teachers) and Developers. The main functions disaggregated and their actors are: i) subject matter -computer science- facilitation (coaches), ii) subject matter content presentation (developers, via online platform), iii) classroom management (teachers), iv) learning analytics and session planning for students and coaches (developers), and v) socioemotional learning facilitation (teachers, coaches, and developers).

Online volunteers are either coaches or developers. They are university students or companies' employees, working in Service Learning or Corporate Social Responsibility (CSR) projects, respectively. Coachers work online 1,2, or 3 hour/week, with some of that time connected in real time with their students. Developers work under a fully flexible schedule (back office staff), and their workloads also vary from 1 to 3 hours per week. There are developers for i) coaching (to students and coaches), ii) software, iii) communications, iv) curriculum, and v) organization. As the facilitators' and developers' workload is low, flexible, online, and technically manageable, attracting alumni that "payback" as volunteers is eased -making the model self-sustaining. The online "Facilitators and Developers Platform" allows all adults to train, prepare and coordinate their performance, and receive weekly feedback and coaching. As a result of this disaggregation and coordination, the students continuously interact with content, peer, and facilitators, in a way that allows them to be the protagonists of their own learning process [4].

2.2 Main pedagogical strategies: One of PRG's pedagogical strategies is Peer learning. In fact, the largest source of crowdsourcing in the peer group itself. All major interactions among students are devised to propitiate such learning, including Pair Programming, with rotating students' roles od Navigator (a de facto coach), and Driver.

Another key strategy used is Project-based leaning. In the first stage of the MaxiMOOC, students work on a code.org course at their own pace in pairs, with immediate, automated feedback. They later integrate the mastered computer science skills into the second stage: the projects where they produce animations, video games, and websites, and socialize them (in the lab and through the internet and social media).

A third pedagogical strategy is the Community of Practice, which thrives in the Lab, with students helping each other, but especially in the Club. Recently launched, the PRG Club deepens relationships among students and between them and coaches, thanks to a more accommodating environment that the Lab's (longer and flexible hours; relationships across several years). In the Club, students at different levels of expertise -up to Sherpas- learn from each other and from their coaches, and thus can provide better support to their peers at the Lab. The activities of the Club have included holidays' projects and will include multigrade and multi-school projects, extra Challenges, hackathons, and inter-school tournaments.

\section{Results}

3.1 The students developed the three attributes of the graduate profile: The attribute of Computational Creators is groomed first during the courses' Computational Challenges. In Ecuador, $95 \%$ on the students solved 80\% or more of the course's 156 Computational Challenges. Similar good performance was achieved in Venezuela before (94\%). This allows students to develop 
computational thinking skills that they later synthesize in their projects, where their facet of creators is maximized. The Collaborative Leaders attribute was reflected by many testimonials given by teachers and administrators about students that evolved from being aggressive, isolated or passive, to working collaboratively and even proactively helping their classmates in their learning process. Peer coaching skills that students developed in PRG even enable them to be tutors in other subjects like mathematics and language. The Permanent Learners attribute's development was reflected in a $20 \%$ improvement in growth mindset, as self-reported in before \& after questionnaires. Anecdotal evidence also included many students that started to enjoy task difficulties and to look at their own mistakes in a constructive way.

3.2 PRG empowers school staff to develop students' 6Cs: Most of the academic (i.e., computer science) learning workload is taken by the MaxiMOOC, the students' peers, and the coaches. Hence, teachers can devote more time to facilitate collaborative and autonomous learning. In Venezuela, the teachers leveraged the peer coaching skills developed by the students to use some of them as peer tutors in other subject areas. That allowed math and language teachers to perform as facilitators -for the first time ever- when teaching their subjects areas.

3.3 PRG also develops two attributes of the graduate profile in volunteers: Coaches develop the Collaborative Leaders attribute as they work 40 weeks as leader/coach alone and within the facilitators' team, and also observe Coaching Developers modeling that behavior. Coaches also develop Permanent Learners' habits like deliberated practice via their weekly cycle of planning, implementing and evaluating sessions, always aiming at increasingly more complex objectives.

3.4 PRG catalyzes outsiders' contribution to the pK-12 system: Unanimous feedback from universities and for-profit enterprises is of praise to PRG for providing a highly structured and impactful solution for volunteers' participating in Service Learning and Corporate Social Responsibility programs, respectively. In the future, we also plan to allow corporations to sponsor activities, so they can enjoy goodwill and viral communications from a grateful educational community, while in exchange provide needed funds for the ecosystem.

\section{References}

[1] Fullan, M., Langworthy, M. (2014). A rich seam: How new pedagogies find deep learning. London: Pearson.

[2] Winthrop, R., McGivney, E. (2015). Why wait 100 years? Bridging the gap in global education. Retrieved from https://www.brookings.edu/research/why-wait-100-years-bridging-the-gap-in-globaleducation/

[3] World Economic Forum (2016). New Vision for Education: Fostering Social and Emotional Learning trough Technology. Retrieved from https://www.weforum.org/reports/new-vision-foreducation-fostering-social-and-emotional-learning-trough-technology

[4] Reid-Martinez, K., Grooms, L.D. (2015). Constructivism as the Driver of 21st Century Online Distance Education. In Encyclopedia of Information Science and Technology, (3rd Ed.) (Vol.3, pp. 2229-2238). Hershey, PA: IGI Global. 